\title{
Slippery Slopes, Moral Slides and Human Nature
}

\section{GARY COLWell Concordia University College of Alberta}

Key Words: Moral, causal, slippery slope, argument, human nature, euthanasia.

Abstract: Causal slippery slope arguments with moral conclusions are sometimes stronger than we think. Their strength may be missed either by overlooking the problems of human nature which support the arguments or, upon seeing the problems, by underestimating their influence upon human behaviour. This article aims to correct the oversight and the misjudgement by looking in some detail at four interrelated problems of human nature which have a direct bearing upon moral causal slope arguments.

Trudy Govier has classified slippery slope arguments into three distinct types:

. . conceptual-relating to vagueness and the ancient sorites paradox, precedental-relating to the need to treat similar cases consistently; and causal

relating to the avoidance of actions which will, or would be likely to, set off

a series of undesirable events (Govier, p.303).

In addition, she classifies a fourth type as "mixed cases" that combines elements of the three distinct types (p. 313f.).

Douglas Walton adopts Govier's classification scheme in his recent book on slippery slope arguments, choosing to call the fourth type "the full or combined slippery slope argument" (Walton, 1992, p.160).

For purposes of this article I shall work within the traditional four-type classification scheme.' My particular interest is causal slippery slope arguments, especially when they are used as/in moral arguments. Still more specifically, I want to investigate some problematic features of human nature which bear importantly upon moral causal slope arguments (MCSA). ${ }^{2}$

Sometimes $M C S A$ present us initially with a reasonable warning. In such cases either the warning ought to be conscientiously heeded or the underlying slope argument deliberately refuted, because nothing less than the well-being of our society may be at stake. Such MCSA should not be casually dismissed as being simply fallacious. ${ }^{3}$ However, in order to assess the strength of MCSA we are required to address four interrelated problems of human nature. And these problems at this time seem to be unresolved from a strictly scientific point of view. But we mustn't take the lack of a precise scientific resolution to these problems as a sufficient basis for thinking that MCSA never present a cogent form of argument. Ideally we should like to have a theory of human nature by which we can assess precisely the predictions which $M C S A$ make. If this ideal cannot be realized now or in the near future, all is not lost. We can still profit from a study of moral analogies from history. 
My first task, then, is to explain with the aid of an example what I mean by moral causal slope arguments (MCSA). Next, I shall outline the four interrelated problems of human nature whose lack of scientific resolution may make us (wrongly) think that $M C S A$ are fallacious. Then I can get down to the main business of discussing these problems and showing how important our awareness of them is to a proper evaluation of the strength of $M C S A$.

\section{Moral Causal Slope Arguments (MCSA)}

A proposal to change a moral practice, or begin a new one, usually elicits opposite responses. Some people become concerned that undesirable consequences will ultimately follow if the proposal is implemented. Other people see no need for concern. This difference in concern about ultimate consequences is what distinguishes the proponents of $M C S A$ from their opponents.

In general, the concerned proponents of $M C S A$ argue as follows:

"If the moral proposal MP is implemented, then it will cause the consequence

$\mathrm{C}_{1}$ to occur, and if $\mathrm{C}_{1}$ occurs, then it will cause $\mathrm{C}_{2}$ to occur, and so on, until

ultimately $C_{n}$ will be caused to occur; and we agree that $C_{n}$ is a morally

undesirable consequence; therefore we should not implement MP." +

A moral proposal currently much talked about is voluntary active euthanasia (VAE). This is a proposal to liberalize laws against homicide, to extend to certain individuals such as physicians the right to kill in particular circumstances, such as those in which terminal cancer patients are suffering unrelievable pain. Euthanitizing is considered voluntary if, for example, the patient is in full possession of his faculties, judges his life to be intolerably painful (or not worth living), is receiving no relief through drug therapy, will die soon anyway, and asks his physician to administer a lethal injection to put him out of his misery. Voluntary euthanasia is considered active if the physician accedes to the patient's request and thus takes an active part in hastening his death by giving him the injection.

Not everyone who objects to $V A E$ does so on the basis of a belief that undesirable consequences will result if the practice is legalized. But many of those whose objection is at least in part based upon this belief proffer $M C S A$. Their concern is that although we may start with $V A E$ for such unfortunates as terminal cancer patients, it will not be long before we slide morally to the place where we are promoting the practice of $V A E$ on non-terminal patients, such as the chronically depressed." And if we permit that, the slide will continue until eventually we shall be killing people without their permission. ${ }^{7}$ At the bottom of this moral slope it will be we, and not the patients, who are determining who is a "burden" to society and whose life is "not worth living". ${ }^{8}$ In the name of mercy, says this moral causal slope argument, we begin with what appears to be a lofty respect for human life and slide to a position of profound disrespect.

$M C S A$ in general, and the argument against $V A E$ in particular, warn against the ultimate occurrence of an undesirable moral consequence in the future. As such, it is a kind of prediction not a normal scientific prediction, but still an empirical prediction broadly speaking."

The undesirable moral consequences predicted by MCSA cannot be known with the same certainty as one can know, for example, that a crystal wine glass will shatter when dropped on the cement sidewalk from a tenth story window. The latter prediction pertains to those inanimate elements whose behaviour is law governed, and the laws are known by the predictor well enough to be used with justified confidence. By contrast, the elements of the former prediction are human beings in different numbers and configurations in society, and about whose future behaviour, both individually and corporately, we are still largely ignorant.

It is here that a mistake in reasoning is sometimes made with respect to the value of MCSA, by calling them, in blanket fashion, "fallacious". Because of our lack of knowledge of the future results of human behaviour we seem to be justified in saying something like the following: "It isn't necessary that the abuses of $V A E$ which you speak of will actually take place. After all, physicians, lawmakers and many politicians are intelligent people, as are the other influential members of our society. All of them realize that in the practice of euthanitizing patients we should go only so far and no farther. And these policy makers are quite able, not only to draw a line in their thinking, but also to not overstep it. Therefore the slippery slope argument against $V A E$ lacks logical force. Its bleak prognostications need not occur."

We shall presently see in greater detail why this is not a strong argument, but for the moment it is sufficient to say that the history of human behaviour tells against it. More importantly, the argument trades upon our lack of knowledge about the future results of human behaviour, concluding from this lack that, because the allegedly dire consequences do not have to occur, a warning that they likely will occur can logically be dismissed. But of course, notoriously, what need not occur may in fact occur, because it often does occur. The critical question therefore is: upon what evidence do we think that the sloping consequences of $V A E$ will or will not likely occur?

So, instead of dismissing the warnings of a moral causal slope argument as being fallacious, grounding our judgement ultimately upon a lack of knowledge, we ought rather to make up the deficit as much as possible in order to assess the strength of the causal slope argument. In order to do that, however, we must face some formidable problems of human nature. The four interrelated problems we shall now outline are not considered to be exhaustive.

One such problem pertains to the often-unhappy separation between thought and action. Having morally right thoughts may be necessary, but is not sufficient to produce morally right actions. Therefore MCSA cannot justifiably be dismissed or pronounced weak on the grounds that the mere production of clear guidelines for the implementation of a potentially dangerous moral proposal such as $V A E$ will be quite sufficient to keep intelligent professionals such as physicians 
from overstepping them. A second problem pertains to the stability and permeance of character traits. The word "permeable" means capable of being permeated, whereas the word "permeance" means "the act of permeating (or pervading)". It's the active voice I want here; and what interests me is the tendency of human motivations to affect not just one type of behaviour, but many, due to the fact that motivations emanate from a personal centre. Since patterns of moral behavior can become fixed character traits whose influence in turn can easily spread to other moral behavior, we may not dismiss MCSA on grounds that either habituated moral behavior can be easily changed or, if not easily changed, at least neatly compartmentalized and contained. For example, we do need to worry about the formation of stable patterns of moral behavior when considering $V A E$, and about the distinct possibility that the influence of such behavior will spread to encompass a larger class of disadvantaged persons. A third problem is desensitization. It should be sobering to realize that a downhill moral slide can occur without our noticing it and without our being able to measure it. Lacking measurable evidence of a slide having occurred over the short term, the critics of some MCSA may conclude mistakenly that in fact no slide is occurring, and be further led to conclude, again misguidedly, that the proponents of these MCSA are simply over-reacting to the proposals for moral change which worry them. A fourth problem is the changeable nature of moral sensitivities. The proponents of MCSA and their opponents usually share at least the same sensitivities about the moral slides which the opponents argue will not occur. If, however, an opponent's sensitivities change, the original debate about the slide will also change. Unless we take $M C S A$ seriously we risk never being able to appreciate their true value, and consequently risk losing forever the lessons of history. And now to a fuller explanation of these problems and a suggested solution.

\section{MCSA and the Problems of Human Nature}

\section{(1) Discrepancy between Moral Thought and Action}

(a) My first example of this problem is taken from an article by Gregory Trianosky. There the author explores the relationship between slippery slope arguments which predict a "progressive deterioration of motivation and inhibitions" following the implementation of a proposal such as $V A E$, and what he calls "ideal-rule-utilitarianism" (Trianosky, p. 414). A lesson that we can learn from the article is that one cannot simply build into one's theory of what it means "to accept a moral code" a guarantee that the prohibition implied by the theory will be followed in practice. In order for ideal-rule-utilitarianism to work as a theory in which, for example, VAE on a limited basis is adopted, it would have to be assumed that the acceptance of the theory involved the complete success of the theory; that is, that everyone who accepted the theory would not only intellectually adhere to it, but also be motivated to follow its prescriptions with respect to the limited practice of $V A E$. But slippery slope arguments which stress the weakening of psychological motivations upon the adoption of, for instance, a qualified code of $V A E$, are questioning the likely success of the code itself; that is, questioning whether it can ever be successfully contained as precisely qualified, no matter what the background theory happens to be which endorses the code. So, one cannot gain a critical victory against the slope argument, suggests Trianosky, by simply saying that "accepting the code of qualified killing" will remove the danger referred to by the slope argument, if the thrust of the slope argument calls into question the very (loaded) notion of the "acceptance of the code in a qualified form". If, like the perfectly just ruler in Plato's Republic, everyone were rationally motivated to act upon the codes prescribed by one's country, then we should have at least a much better guarantee that a precisely contained policy of $V A E$ would be adhered to after being accepted. But alas, humans in real society are not so rationally motivated.

(b) Another example of how the discrepancy between moral thought and action bears importantly upon MCSA is found in an article by E.M. Berger and B.M. Gert. The authors consider "several of the ethical issues that have been raised by the application of recombinant DNA technology to humans"(p. 668). They address two major concerns:

The first major concern is that no clear cut distinction can be made between negative eugenics, the systematic elimination of undesirable genes and positive eugenics, the systematic improvement or perfection of the gene pool (p.670).

... The first argument against gene therapy is that if we use the procedures to

cure sickle cell anemia and other genetic disorders, we will be unable to draw the line against using gene therapy to improve our species (p.674).

At this point, however, the authors do not see an insurmountable problem: "The position taken here is that one can draw such a line ..." (p. 674). By analysing the concept of "malady" they argue that a non-arbitrary line can be drawn between negative and positive eugenics. Thus, they believe that the challenge of a conceptual slope argument can be adequately met. But this does not reveal the full extent of their concerns.

A second major concern is that "eliminating so-called 'bad genes' will lead to a dangerous narrowing of diversity in the gene pool" and attempts to "cleanse the germline over tens or hundreds of years will lose traits that we later realize are important" (Rifkin, 1983).

In the last section of the article, appropriately titled "Real World Considerations", the authors express their worries, not about being able to draw conceptual lines, but about the temptations and motivations of researchers: such matters as are often identified by causal slope arguments that are applied to moral issues. If one could be sure that germ-line gene therapy would be strictly used for only those very few cases in which, with present knowledge, it is warranted, then one could feel confident that no foolish risks would be taken which might affect "the genetic make-up of an unlimited number of people" (p.679). 
However, past experience has shown that exciting new technology, including medical technology, generates pressures for its use (679). . . [ [I]n the real world researchers will overestimate their knowledge of the risks involved and hence will be tempted to perform germ-line gene therapy when it is not justified (p.680).

The authors are not worried about germ-line researchers not being able to delimit the concepts of positive and negative eugenics, but instead, about the nonconceptual forces at work within the human nature of the researchers: presumably such motivational forces as the desire to be first to create something new, perhaps by using a new technology to produce a new genetic form. ${ }^{11}$ As well, there exists for the researcher the temptation to go where his knowledge cannot justify his going, a temptation resulting perhaps from a desire for fame or fortune or from just curiosity. The non-conceptual motivators within human nature are plentiful and powerful and one needs to acknowledge them when assessing slippery slope arguments. Therefore, it will not do to criticize the causal slope argument against the practice of germ-line gene therapy on grounds that the researchers know where to draw the line, because there are other influences than thought and knowledge at work within the researchers which may predominate over these conceptual influences. Since the researchers' knowledge of where to draw the line by itself is not a guarantee that the line will not be crossed, it should not be taken as such in a criticism of the slope argument against germ-line gene therapy. Indeed, a more general point can be gleaned from these observations. In an attempt to criticize $M C S A$, an appeal to the likelihood that people will have knowledge of the specified conditions for the proper use of a new moral practice, may be either (a) beside the point or (b) not to the main point of the slope argument.

We shouldn't think that the problem of the discrepancy between moral thought and action relates to only such exotic ethical issues as germ-line gene therapy. In fact it afflicts many common social and ethical issues, of which I have space to discuss only one.

(c) Undergraduate students who are caught cheating on an exam or plagiarizing an essay almost always know that what they are doing is wrong. Yet they do it anyway. They might try to weasel out of the embarrassing situation by arguing that they were not doing what they are accused of doing. But they will not usually argue that what they are accused of doing, if in fact they were doing it, is morally right. And this is especially so if previously the wrongness of the action has been emphasized. Furthermore, this kind of immoral behaviour does not disappear when students achieve graduate or faculty status. Very well educated people cheat too, perhaps at a startling rate.

The results of a survey titled "Ethical Problems in Academic Research" were published recently in the American Scientist (Swazey et al, pp. 542-53).

[T] he Acadia Institute Project on Professional Values and Ethical Issues in the Graduate Education of Scientists and Engineers, with grant support from the National Science Foundation, surveyed 2,000 doctoral candidates and 2,000 of their faculty about their experiences with 15 different types of ethically questionable behavior. We sampled doctoral students and faculty from 99 of the largest graduate departments in chemistry, civil engineering, microbiology and sociology ... our questionnaires sought rates of exposure to perceived misconduct [p.542].

The rate of response for graduate students was 72 percent (1440) and the rate for faculty was 59 percent (1180). The general conclusion of the authors was that

although misconduct is not rampant, examples of behavior that fall into the National Academy's definition of science-related misconduct (Category 1) are not rare. Between six and nine percent of both students and faculty report that they have direct knowledge of faculty who have plagiarized or falsified data. Faculty reports of plagiarism and falsification by students are considerably higher; nearly a third of faculty claim to have observed student plagiarism [pp. 544-45].

Note that the above statistics refer to just the misconduct of Category $1 \mathrm{kind}$, including "fabrication, falsification, or plagiarism, in proposing, or reporting research" (p.542). The Category 2 kind of misconduct included "questionable research practices, such as keeping poor research records or permitting honorary authorship." And the Category 3 kind included "behaviour such as sexual harassment and violations of government regulations, which may take place in a research context ..."(542-44). Taking into consideration all 15 types of ethically questionable behaviour covered by all three categories of misconduct, the authors had this observation to make about the results of their survey:

When we accumulate reports of all types of misconduct and questionable research practices by faculty and students, we find that 44 percent of students and 50 percent of faculty have been exposed to two or more types. ... The pervasiveness of these experiences is greater than would be predicted by those who focus on the dramatic but rare instances that are publicly reported and acted on (p.552).

There is no evidence from the results of this survey to suggest that the doctoral students and faculty who reportedly engaged in misconduct of the type found in Category 1, for example, did not know that what they were doing was wrong. Indeed, an understanding of the meaning of "misconduct" by those who completed the questionnaires provides prima facie evidence that their colleagues whose perceived misconduct they reported did know that it was wrong, because the subjects were drawn from the same educational class and location as the perceived violators. While it is reasonable to assume that nearly everyone about whom perceived misconduct was reported knew that he or she should not engage in such behaviour, given the evidence of the survey, it would not have been reasonable to assume that nearly everyone would refrain from engaging in such misconduct. One of the valuable functions which $M C S A$ perform is to challenge moral innovators to take seriously the kind of discrepancy we have observed here when they are thinking about implementing a new moral practice.

(d) Our last major example of discrepant behaviour comes from the findings of the Remmelink Commission. In January of 1990 the Dutch Ministers of 
Health and Justice set up a commission to collect detailed information on the practice of euthanasia by physicians in The Netherlands. The commission took its name from its chairman, Prof. J. Remmelink, Attorney General of the Dutch Supreme Court. Since the commission's report appeared in September of 1991 several interpretations of the data have been published. Some interpreters are not worried by the numerous cases of voluntary and non-voluntary euthanasia that have been reported (ten Have, et al, van der Maas, et al). Others, however, are very worried and are highly critical of what is happening in The Netherlands (Fenigsen). Yet others take a position that might be seen as a blend of the previous two positions (Sneiderman). But, whatever the interpretation, all the studies with which I am familiar have acknowledged that in 1990 non-voluntary euthanasia was practiced on 1000 patients. This is especially striking given the following three facts: (1) Non-voluntary euthanasia was (and is) prohibited by the Dutch Penal Code-it was against the law and the physicians who euthanitized 1000 patients without their consent knew that they were breaking the law; (2) Non-voluntary euthanasia was (and is) prohibited by the Royal Dutch Medical Association's own code of medical ethics, and of course the physicians knew that they were contravening this code as well; (3) The Netherlands already had one of the most liberal standards in the world for the practice of euthanasia. The sum of the matter for purposes of our study of MCSA is that, while knowing clearly the prohibitions against practicing non-voluntary euthanasia on their patients, physicians in 1000 cases did so anyway." This does not inspire much confidence in the position of those who tell us that the moral slide we worry about in the matter of euthanasia can be prevented by making a law which will conceptually delineate who may and who may not be put to death by physicians.

(e) To try to account for the cases of moral discrepancy that we have observed in sections (a)-(d) we can invoke at least two theories from the social sciences. The first is the psychological theory of cognitive dissonance which I shall explain below; the second is the sociological (or social psychological) theory of symbolic interactionism which I shall explain in endnote \#13. A few brief comments on each of them may help us to better understand the potentially destructive elements of human nature to which $M C S A$ indirectly point.

The theory of cognitive dissonance was proposed by Leon Festinger in $A$ theory of cognitive dissonance (1957). Festinger predicated the theory on the assumption that a person is motivated to maintain consistency or consonance. among pairs of relevant cognitions, where a cognition refers to any knowledge or belief about self, behaviour, or the environment. Cognitions $\mathrm{X}$ and $\mathrm{Y}$ are regarded as dissonant "if not-X follows from Y" (Campbell, 249-50).

For example, a person may hold the cognition "I smoke" $(X)$ as well as the cognition "Smoking causes cancer" $(\mathrm{Y})$. Not-X follows from $\mathrm{Y}$, not in a logical sense but presumably in the sense that if one believes $Y$ then one ought to be led (psychologically) to value and practice not-X. According to the theory, the inconsistency that is produced by holding $X$ and $Y$ is thus not a logical inconsistency. And even then, we can say that $X$ and $Y$ will produce dissonance only if it is assumed (usually safely) that the person holding $\mathrm{X}$ and $\mathrm{Y}$ does not want to get cancer (p. 250).

There are various ways in which a person can reduce cognitive dissonance. "Dissonance may be reduced by altering one of the dissonant cognitions [by stopping smoking], by reducing the importance of the dissonance [by decrying the evidence linking cancer to smoking], or by adding new information which is consonant with one of the discrepant cognitions or which somehow 'reconciles' the two dissonant elements [by saying to oneself that the reduction of stress by smoking makes the risk of cancer worthwhile]" (bracketed information added, p.249). ${ }^{12}$

Although I do not have empirical data on the reasons that the physicians in The Netherlands gave for breaking the codes which were supposed to govern their medical practice, it is not difficult, using the theory of cognitive dissonance, to interpret their behaviour. Presumably some dissonance would have been produced by the physicians as they held the inconsistent cognitions "I practice(d) non-voluntary euthanasia" and "the codes governing my profession prohibit nonvoluntary euthanasia". Perhaps they reduced the importance of the dissonance by saying to themselves that their governing codes were not worthy of respect because, for example, the codes did not realistically deal with the irreversibly comatose patient. To 'reconcile' the dissonant cognitions they might have said that the feeling of peace which they gave the distraught relatives of the comatose patient, as well as the money they saved the government, justified their killing the patient without his or her consent. The physicians could also have altered the first of the dissonant cognitions by ceasing from practicing non-voluntary euthanasia. And of course they could work politically to alter the second one as well. ${ }^{13}$

Whatever theory one draws upon to explain the discrepancies between moral thought and action which we have examined in (a)-(d), the important lessons for our study are these: (1) human beings do create these discrepancies; (2) human beings devise ways of camouflaging or living with these discrepancies; and (3) these discrepancies are both more numerous and more significant for social life than any easy dismissal of $M C S A$ as fallacious will allow.

We may summarize the first problem as follows. Knowing where to draw a conceptual line is not the same as having the causal restraint to keep from crossing it. Nor is knowing about the need for such restraint the restraint itself. Consequently, criticisms of MCSA on grounds that people "know better" than to let a controversial moral practice get out of hand, are misguided. One of the virtues of MCSA is that they urge moral innovators to acknowledge the often overlooked discrepancy between knowing what is right and doing it.

\section{(2) The Stability and Permeance of Character Traits}

We can view human behaviour as lying on a continuum which has at one end (A) the type of behaviour over which the agent has complete control, and which has 
at the other end $(Z)$ the type of behaviour over which the agent has no control. The examples in (1a-e) above illustrate the type of behaviour found near the Aend of the spectrum. Although many academics knowingly misrepresent data or steal ideas from others, they are not constrained to do so. And although many physicians knowingly break the law, and use psychological techniques to rationalize their behaviour, they are not forced to do so. In thinking about the strength of MCSA we need also to think about the type of behaviour found near the Z-end of the continuum. We need to worry about the negative, stable and permeating character traits which profoundly affect human behaviour, traits over which a person's decision making ability may have a dangerously diminished or, in some few instances, nearly complete lack of control. 1+

For a very long time common wisdom has implied that moral and immoral acts issue from a personal center which is formed by a pattern of behaviour we often refer to as "character". If someone were to babysit your children and you knew that that person stole one of your valuable possessions, and then lied to cover it up, you would not likely say: "Well, we'll make him return it and reprimand him for the theft, but we'll keep him on because he really likes the kids". On a larger scale, if the president of a democratic country authorizes the break-in of the national convention headquarters of an opposing party, and lies to cover it up, most of the public will not likely say "Give him a severe reprimanding; but keep him on because he is so efficient at running the country". The main reason that most people do not respond in these ways is because they believe in what may be called the (a) stability and (b) permeance of character traits, whether or not they use these words.

The moral behaviour of individuals or groups of individuals, including their attitudes and actions, can achieve both (a) an unchangeable and (b) a pervasive quality when engaged in over a significant period of time. Such behaviour can issue in relatively fixed character traits which tend to form a web of connections with other traits at the centre of one's personality. Because people's behaviour, once stabilized, is not easily changed, and because the influence of such behaviour is not easily compartmentalized, $M C S A$ cannot justifiably be dismissed on presumed contradictory grounds: namely, on grounds that because stable character traits can quite easily be changed and their influence easily contained, there is little need to worry even if the projected consequences of MCSA come to pass. Lacking an appreciation for the potentially destructive qualities of stability and permeance in human character traits, opponents of MCSA proceed with a false sense of confidence about the strength of their anti-slope arguments. (In section (4) we shall consider the possible stabilizing and pervading effects upon our behaviour which may have been produced by $20-30$ years of liberal policy on taking prenatal human life.)

(a) An illustration of the relative stability which negative character traits can reach is found in Bruce Levitt's account of the life of Norman ("Red") Ryan (1895-1936), which was reported widely in The Canadian Press. ${ }^{15}$ "Red Ryan was a killer, bank robber and prison escapee but, most of all, he was a con artist who charmed a prime minister into visiting him in prison and talked his way out of one of the toughest jails in North America". He began his career in crime at the age of 12 when he stole a bicycle. This was followed by chicken-stealing, for which he was sent to Reform School. At the age of 17 he was sent to Kingston Penitentiary for $31 / 2$ years for "burglary, theft, shopbreaking and shooting with intent to maim." After that he returned to Kingston for 12 years for a payroll robbery. He was released to join the army, but after World War I was over he returned to Canada. Then he returned to robbing banks, was caught and was sent to Kingston for 25 years. He escaped from prison, was apprehended, given 30 lashes and sentenced to life. Then a great 'change' took place. As a model prisoner he mended mailbags and even became an altar boy. The Prime Minister R.B. Bennett visited him in "prison and was "greatly impressed". After 11 years he was released. Working as a used-car salesman, he wrote a series of widely acclaimed articles for The Toronto Star on the theme "crime does not pay". He was shot to death in an attempt to hold up a liquor store. Not only was a policeman killed in the shoot-out, but it was discovered that Ryan's gun was the one that had killed a father and son in an earlier car-theft case. In one of Levitt's concluding remarks he says, "The incident was a disaster for the Canadian ticketof-leave system .... Thirty years later, the case was still used as an argument against the entire concept of early release from prison."

Character traits such as dishonesty can become relatively stable after being formed habitually over a certain period of time. That period of time cannot be generally formulated with anything like the precision we could wish to have when assessing the quality of MCSA. But this is not a good reason to put blinders on with respect to the fact that such stability is sometimes reached in the lives of people and works to the detriment of society. Moreover, it is a bad reason for dismissing MCSA as fallacious. Evidence other than precise scientific evidence can be, and on a daily basis actually is, used to make prognostications about the trustworthiness of persons of disreputable character. MCSA can be non-fallacious and cogent on grounds other than precise scientific ones. ${ }^{16}$ Perhaps the best we can do at this stage of the development of the social sciences is to look for analogies in history; we shall take up this approach in section (4).

(b) In assessing MCSA, the permeance of character traits is just as important as their stability, and its importance is more often overlooked. Sometimes a naive, unreflective view of human nature prevails when discussions of moral slides take place. It's as though a person's character were composed of a large number of wells, perfectly sealed and isolated from one other. Rising up from each well is a pipe, also perfectly sealed from the other pipes. Together they look like a cluster of organ pipes. The motivation to steal or not to steal rises through only one pipe; the motivation to tell the truth or to lie rises through a different pipe; and soon on, through the range of all the virtues and vices. There is no permeance from the well of lying to the well of stealing, and so on. Thus, motivations from the well of lying, for instance, cannot rise through the pipe of stealing. As a consequence we do not have to worry that an inveterate liar's lying 
will have any adverse effects upon other elements of his character, such as his attitude toward others' possessions, or upon the network center of his personality from which his behaviors emanate.

Nobody with even a modicum of wisdom about human nature would believe such a thing, if they thought about it. Unfortunately, most people are not thinking about it. And this neglect among the opponents of $M C S A$ can make them think that their criticisms are stronger than they actually are. ${ }^{17}$

\section{(3) Desensitization}

Behaviour therapy seeks to develop ways of eliminating ("unlearning") maladaptive or abnormal behaviour. One of the techniques which the therapist uses is systematic desensitization (SD). This "is a humane way of extinguishing a classically conditioned anxiety response" such as a debilitating fear of dogs. "In order to extinguish the anxiety, $[S D]$ uses a gradual approach based on the learning principle of counterconditioning ... the client learns to relax instead of feeling anxious in response to the anxiety-arousing stimulus" (Huffman, et al, p.525).

Given the fact that "it is physiologically impossible to be both relaxed and anxious at the same time", the aim of the therapist is to get the patient to maintain a state of relaxation while visualizing a hierarchy of anxiety-arousing images. For example, the images used to eliminate the fear of dogs may range in graduated sequence from pictures of a dog in a magazine to an image of the phobic person petting a large dog. ${ }^{18}$

The same principles that enable $S D$ to work inside a therapist's office are operative outside as well. People can be rendered insensitive to stimuli produced by a behaviour simply by engaging in that behaviour, usually, but not necessarily, over a long time. A soldier who first abhors killing can lose his distaste for it by repeatedly engaging in it. Four-letter words which originally shock people when they hear them in the movies for the first time lose their shock value after many such movies have been seen. The taboo of pornography can be worn off by being repeatedly exposed to it, and so on.

Carver and Scheier conclude from their discussion of aggression that the repeated viewing of aggression makes people more likely to use it in their own lives:

$[R]$ epeated exposure to violence desensitizes observers to the implications of human suffering. The shock and upset that most people normally associate with acts of extreme violence become extinguished, by repeated presentations of violent stimuli .... As people's emotional reactions to violence are extinguished, being victimized (and also victimizing others) may come to be seen as an ordinary part of life. It's hard to study the effects of such a process in their full breadth. If such effects are pervasive, however, they constitute a real threat to society" (p.383-84).
The authors do not discuss the difficulty to which they briefly refer, but given the context, they presumably mean that the long-term effects of viewing aggression usually cannot be studied in a controlled, laboratory setting. ${ }^{12}$

More disturbing, however, is the opposite phenomenon: the undetectability of desensitization over the short term. Often the basic elements of the process are minutely incremental and imperceptible when examined individually or in a short series. For example, not much will be proven about the formation of character by trying to measure the violent behaviour in children after they have been exposed to a single, half-hour, violent T.V. program. But there is at least good anecdotal evidence to show that hundreds and thousands of hours of viewing violent programs will have a long-lasting undesirable effect upon child development. ${ }^{20}$

This reveals one of the limits of scientific methodology. By taking the longterm anecdotal view one may see the truth, but may not be able to certify it with scientific measurements. On the other hand, by taking the short-term view one may produce impressive measurements (or lack thereof) but not see the truthnamely, that the minutely incremental elements of some destructive processes cannot be measured, although their cumulative effects will eventually be seen by all. ${ }^{21}$ A troubling result follows from this.

Proponents of $M C S A$ will not be taken seriously without having presented some data to justify their warnings about the likely occurrence of the moral slides they predict. If, due to methodological limitations, the proponents cannot in principle now provide the kind of measurable data which the critic requests, then the critic may well overlook the possibility that desensitization has occurred and conclude that no destructive force is at work. On the assumption that desensitization in some cases is an incremental process, the apparent strength of the criticisms against MCSA may be illusory; and yet without either side of the debate realizing it. Moreover, after the long-term destructive work of desensitization has become evident, and data are available, it may be too late to use them or derive any benefit from the slope argument (more on this in section (4)).

For example, today there are people who worry about our chief care givers becoming desensitized to killing their patients, such that, over the span of a few decades it will become relatively easy for them to prescribe, not just $V A E$, but also Non-VAE for more and more cases which are now positioned high on the hierarchy of forbidden acts of killing (e.g., the mentally retarded, paraplegics, the economically desperate, etc.).

To those who say that it couldn't happen, the proper response is, to some degree it already has. ${ }^{22}$ Physicians in The Netherlands have already moved up the hierarchy from $V A E$ to Non-VAE, and from killing terminal patients to killing ones who are not terminal. The latest development was announced recently in The Hague and picked up by The Associated Press:

The debate over euthanasia flared anew Wednesday after the Supreme Court refused to punish a doctor who supplied a fatal dose of sleeping pills to a severely depressed but otherwise healthy woman. The court ruling Tuesday 
broadened the country's euthanasia guidelines to include the mentally or emotionally ill. ${ }^{23}$

However, we musn't lose sight of the main point. At each stage of the process of liberalizing the practice of euthanasia we may not see a dramatic change in the attitudes and beliefs of physicians. But after a few decades of increasingly liberal practice, their keen sensitivity to the great value of human life could be all but extinguished. If and when it is extinguished, we shall not be able to point to the shocking results because then the physicians will no longer consider them to be shocking, and hence the slope argument will have become irrelevant.

\section{(4) Analogies from the Past: The Lessons of History}

We have seen that MCSA should be taken seriously before they become irrelevant because they force us to face the possible negative cumulative effects of some liberalizing proposals for moral and social change. However, in order to adjudicate the worth of $M C S A$ we seem to need to be able to predict precisely what people in society will do. But this is an unrealistic wish, for several reasons. First, the enormous number of variables militate against it: we can't put the whole society under a microscope. Second, we have seen that people do what they know they shouldn't do and resist doing what they know they should do. This greatly frustrates predictions. Third, measuring destructive moral behaviour over the short term may well be impossible. However, since accurate predictions of long-term destruction seem to require such measurements we may be tempted to dismiss $M C S A$ as being not cogent.

While not forgetting the value of some controlled studies of behaviour which bear upon the large-scale moral behaviour of persons in society, perhaps one of the most effective things we can do is to learn the lessons of history, that is, to look for past analogies of the kind of moral slide we think will occur in the future.

For example, there was a time early in the abortion debate when the vast majority said that abortion should be used in cases where the mother's life was in danger; far fewer said that it should be used in cases of rape, incest and mental or physical deformity; and very few said that it should be used as birth control or for the sake of simple convenience.

Now, of course, attitudes have changed dramatically. A much smaller proportion agonizes over the morality of what is thought to be a regular medical procedure. Abortion today is a live option for a much larger proportion of the population than it was thirty years ago. ${ }^{2+}$

Suppose that a critic were to employ a moral slope argument against implementing a proposal for $V A E$. He worries about the possible gradual erosion of human sensitivities against killing people. And he does so upon the basis of what has transpired over the last three decades in the case of abortion. Just as sensitivities against taking pre-natal human life have been eroded, he argues, so will the sensitivities against the taking post-natal human life: particularly those lives which do not fall into the category of "fatal conditions with no will to live", and which our moral sensitivities now want to protect, but which also, in three decades hence, our changed sensitivities may not want to protect. What responses will such a critic meet?

First, it might be argued that the recent history of abortion and the possible history of euthanasia are not parallel, so that even if we think that the former case is lamentable, the latter case will not occur. In light of the data we have on the practice of abortion over the past three decades, good reasons would have to be given for this alleged disanalogy to make the response cogent. ${ }^{25}$ But a second response might deny the assumption in the first response, and in doing so lead us to a most urgent problem. It might be said that the progressive changes in attitudes toward abortion should not be viewed as a lamentable development, but instead should make us realize that our thirty-year-old sensitivities against taking pre-natal human life were mistaken. In fact, a great many people are saying this today. By the same reasoning, however, what are now strong sensitivities against "putting dear old granny away" because the kids really need the money, may become almost entirely eroded in thirty years' time, such that we shall then look back and say again that we were wrong to lament such a possibility; for when it is realized we may find it quite acceptable.

One way of dealing with this objection is to say, "So be it". Consistent though this response is, it has horrific implications. For we can also say about any inhumane practices that if our sensitivities and corresponding moral evaluations change with respect to them, they will become morally permissible. The horrors of "ethnic cleansing" and the systematic removal of the "burdens" of society could be upon us again, and this time with the support of a firmly entrenched theory of ethical relativism.

If we do not take MCSA against proposals for radical moral change very seriously before the proposals are implemented, we run the grave risk of never being able to correctly judge the proposals. For in waiting to see what happens, in order to adjudicate the merits of the moral slope argument, the original debate may have disappeared irrevocably. The sensitivities earlier shared by proponents of the slope argument and their opponents alike, regarding the undesirable excesses which the proponents have projected, will then no longer be shared by both; the opponents and their allies having long since lost their sensitivities, while judging that their earlier possession of them was unenlightened. ${ }^{26}$

However, an opponent cannot change his mind with impunity. He must pay the price of living with, and acting upon, an inconsistent argument; and worse, possibly contributing to the dehumanization of society.

Either the opponent's own prediction will be right, that the desensitization will not take place and the ensuing destructive behaviour will not occur, or his prediction will be wrong, in which case desensitization will take place and the destructive behaviour will occur. 
Unfortunately, because of the insidious character of this protracted debate, even if the opponent is wrong, he may still claim to be right on the grounds that his original sensitivities, about whose denied erosion he was mistaken, were wrong ones to have in the first place.

But, if it was wrong for the opponent to have these sensitivities in the first place, then his original anti-slope argument, which presupposed the rightness of having such sensitivities, turns out to have been groundless, in which case he ought not to have opposed the original slope argument in the way he did. The opponent might have used another argument, but because he used this one, namely, that the sensitiyities would not be eroded, he assumed the rightness of holding those sensitivities as well as the wrongness of the behaviour which the holding of those sensitivities is designed to discourage.

So, either he was right about the sensitivities and wrong about his anti-slope argument or he was wrong about the sensitivities and should not have objected to the slope argument in the way he did. But, if his argument was wrong and his sensitivities were right, to be consistent he would now have to argue for a reversal of the destructive liberal behaviour which he said would never come about. But the danger is that he won't do this because he now thinks that the present liberal behaviour is acceptable (cf. The Netherlands' physicians). If he was wrong about his sensitivities, and now claims to be right in holding the liberal position, which originally he said would never transpire, he does so on a completely different basis from the one on which he first opposed the slope argument. But then, there turns out to be no real basis at all-or at least it's an ever-shifting basis which permits no final adjudication of the argument. The rightness and wrongness of sensitivities are in a state of complete flux.

The problem here is not merely that time is a culprit, that we are frustrated when we try to look at the cogency of anti-slope arguments from two different temporal perspectives. Rather, it has to do more centrally with the real possibility that human sensitivities, unless preserved by conviction and protected by law, will change over time. The cogency of any moral argument depends on the moral sensitivities of those who evaluate it. Change the latter and the former will change as well. ${ }^{27}$

\section{Concluding Remarks}

No algorithm exists for determining which are good and which are bad MCSA. This is because of the number and inscrutability of the variables in the situations to which MCSA refer, together with human inability to predict what the proposed changes involving the variables will ultimately produce. Even so, what I have been arguing against is the view that because we cannot make precise scientific predictions about human behaviour on a social scale, we need not worry about the dire consequences which the proponents of MCSA project. I have been criticizing what might be called an argument from ignorance: because we don't know scientifically that certain sloping consequences will occur, in effect we know that they won't occur, or in effect we have good evidence to think that they won't.

Lacking an ability to measure precisely the potentially destructive influences of certain aspects of human nature does not mean that these influences do not exist or that they can be safely ignored. On the contrary, when premises stating one or more of the four interrelated problems of human nature are added to $M C S A$ which have at least some plausibility, the $M C S A$ are accordingly strengthened; they are harder to reject as fallacious. And what the predictions of $M C S A$ lack in precision perhaps they can gain in accuracy through a careful analogical study of moral history. If these rough judgements save us from inhumanity and social misery they will have served their purpose exceedingly well.

Especially sobering is the prospect that if we do not early address the dire possibilities which some $M C S A$ project, such as the predicted negative results of legalizing $V A E$, we run the grave risk of never being able to debate the issues with our current moral sensitivities in tact. ${ }^{28}$

\section{Notes}

This is not the only classification scheme that could be adopted. For example, both Rachels and Lamb categorize slippery slope arguments into logical and psychological arguments (Rachels, pp. 69,70; Lamb, p. 3f.). And Glover, as reported by Govier, uses the distinction between logical and empirical slippery slopes (Govier, p. 306)

${ }^{2}$ The use of the term moral causal slope argument is itself not entirely unproblematic. First, the metaphorical nature of the term needs to be born in mind. The slope down which people may slide, due to the morally questionable behaviour in which they engage, doesn't cause anything. It is the (im)moral behaviour which both creates the slope and causes the slide. Furthermore, the notion of cause is not unambiguous in its present use. It can include both Aristotle's efficient and final cause; and regarding the former, it can include, on the one hand, both naturalistic and deterministic causes (blind causes) which we see in nature and formulate in physical laws, and on the other hand, personal or agential causes.

As an illustration of the range of causes we have in mind, consider the heroin addict's road to addiction. Before using hard drugs he may set out "to have a good time and escape the stress of life" (final cause). With this in mind he may deliberately choose heroin for the purpose of effecting his escape (efficient (agential or personal) cause). At some point down the road he may acknowledge his sorry state, want to stop using the substance, but be unable to do so because he is "hooked" (efficient (naturalistic and deterministic) cause). The powerful cravings now active in his system cause him to continue to use heroin in a different way than his deliberation and choice caused him to take it up in the first instance. So, the causes to which we refer, and which bear upon the behaviour of the moral agent(s), may be of either an internal or external nature; and regarding the former, be of a relatively determined or non-determined kind.

3 The thesis of Walton's book is "that slippery slope arguments are sometimes fallacious, but usually not" (p.29). He argues that we ought to evaluate slope arguments as being relatively weak or strong, but rarely as being logically fallacious (pp.64f., 69f., 234f.). The clear implication is that there can be good slope arguments. Whether or not a causal slope argument is good (strong) depends upon the empirical evidence supporting it, or not, as the case may be (pp. 75-78). 
${ }^{4}$ Our conversational arguments are often a mixture of indicative and subjunctive statements. For example, we say such things as this: "If you do $\mathrm{X}$, then $\mathrm{Y}$ will follow; and if $\mathrm{Y}$ occurs then $\mathrm{Z}$ will follow; and $\mathrm{Z}$ is an undesirable result; therefore you should not do $\mathrm{X}$ ". This is not a deductive argument. However, if we assume that (a) both parties in the discussion agree that the causal sequence will take place, and that (b) it is plausible to argue that the sequence will in fact take place, and that (c) both parties accept the hidden premise that "an undesirable result is one that you should not want to occur", then the mixed conditional conclusion would seem to plausibly follow: "if $Z$ is an undesirable result, then you should not do X".

As it stands, my general statement of MCSA may not be strictly identified with any of the valid argument forms, modus ponens, modus tollens or hypothetical syllogism. This is mainly because the antecedent $(\mathrm{s})$ is not affirmed and the consequent is not denied. Still, I think it correct to say that there are three aspects of this general statement which respectively bear a strong resemblance to the three argument forms just mentioned.

Walton makes a similar observation, at least about the first two valid deductive forms. After stating that the causal slippery slope argument is "a species of the argument from consequences" he further argues that "[t]his negative argument from consequences has a general form of argument that can be identified with modus tollens: If $\mathrm{A}$ then $\mathrm{B}$; not-B; therefore not-A. But $A$ and $B$ stand for proposed actions or outcomes of actions rather than propositions and the conditional is not the material conditional of deductive logic.... Thus although the causal slippery slope argument has, in its outer shell, a deductively valid structure as a sequence of modus ponens subarguments, its inner logic (the basis of whether it is a strong or weak argument in a particular case) is inherently pragmatic" (Walton, pp. 90,91 ; also see pp.148,149).

${ }^{5}$ For a fuller account of the distinctions between the different kinds of euthanasia, read Rachaels, pp. 38, 39. To see the distinction between "deliberate killing" and "letting-die" read Walton, 1981, pp. 70, 71 .

${ }^{6}$ The first draft of this paper was written before the recent announcement came from The Netherlands saying that the country had broadened its euthanasia guidelines to include the mentally and emotionally ill. See pp 13-14, note \#23.

' There is evidence for the belief that, in The Netherlands this stage in the moral slide has been reached already. This is dealt with in (1)(d).

${ }^{8}$ The possibility of moral despots determining which lives "are not worth living" is a recurrent theme in David Lamb's work. In Chapter 2 he discusses the horrors of Nazi genocide and the possible parallels which can be drawn between pre-Nazi society and our own.

"I discuss three uses of the word "predict" in my recently published article "Freedom, Determinism and Circular Reasoning", Argumentation, Vol. 8, No. 3, 1994, p. 262.

${ }^{10}$ This is not to say that they should not be worried about the delimitation of the concepts of "good" and "bad" genes. For this involves making moral value judgements which lie largely, if not entirely, outside the province of biology. Who defines what a "bad" gene is, and according to what evaluative criteria, should be a troubling matter, not just for the geneticist, but for everyone. And the geneticist, with his biological expertise does not ipso facto have special insight into what human characteristics are good or bad for society. Again, "conceptual" or "combined" slippery slope arguments, as important as they are, are not our main concern.

${ }^{11}$ It could be argued that, although the physicians knew what the law said, that from a legal point of view they were not supposed to kill their patients without the patients' consent, nonetheless, they did not believe, and hence did not know, that they should not break the law, because they believed the law was unjust or otherwise unworthy of respect. While this could be true, it does nothing to alleviate our anxiety about the silent, wilful disobedience on the part of physicians who break their society's euthanasia law. Indeed, it exacerbates the problem of the slippery slope. With what moral authority will they be able to encourage subsequent generations of physicians to hold the legal line, when that line itself was originally drawn illegally? Let's assume just for the sake of argument that the physicians hold a new line against euthanasia which they have drawn illegally; and let's suppose that their illegally drawn line becomes legally adopted. The main point for our study remains, that those assessing MCSA should incorporate into their judgements the clear fact that drawing a moral line, as important as that is, will not by itself keep people from crossing it. One of the clearest indications that the successful responses to conceptual slope arguments are not adequate to solve the problems of $M C S A$ is that currently, although we have laws forbidding $V A E$, many people want to change them. A line has been drawn to set the limits of moral practice, for a very long time; but now, many people want to redraw the line.

${ }^{12} \mathrm{~A}$ further example is the smoker who says "my uncle smoked all his life and he lived to be 95". Here again the dissonance is reduced with incorrect thinking: rejection by a rare exception.

${ }^{13}$ The essence of Symbolic Interactionism (SI) is harder to capture in a few words. Part of the difficulty lies with the considerable diversity of viewpoints found among sociologists who conduct research within the general framework of SI. We shall therefore try to identify some of the essential features of SI which bear upon our investigation of moral slides.

The term "symbolic interactionism" was invented by Herbert Blumer (1937) whose ideas about SI stem directly from the work of George Herbert Mead. Since Mead, SI sociologists generally have viewed society as "a web of communication":

Society is interaction, the reciprocal influence of persons who, as they relate, take into account each others' characteristics and actions; and interaction is communication. Interaction is 'symbolic,' conducted in terms of meanings persons develop in the course of their interdependent conduct... Persons act with reference to one another in terms of symbols developed through interaction, and they act via the communication of these symbols. Society is a label aggregating and summarizing such interaction. Society does not 'exist'; it is created and continuously recreated as persons interact.... Society and individual presuppose each other in that neither exists except in relation to the other ... human beings can and sometimes do take themselves as the object of their own reflection, thus creating selves, doing so from he standpoint of others with whom they interact. [Stryker, p. 2127]

This last mentioned feature of reflexivity has special significance not only for SI but also for our study. Persons can and do create society through their interactions because they possess the capacity to view themselves from another person's perspective; that is, they can imaginatively project themselves into the perspective of another and look back at themselves through the other's eyes. This is called role taking. The value of this in social interaction is that one can articulate how what one does will be received and accordingly adjust one's behaviour as needed or desired.

Because roles often lack consistency and concreteness, but actors must organize their behavior as if roles were unequivocal, interaction is also a matter of role making, creating and modifying roles through devising performances in response to imputed roles of others (Turner 1962) [Stryker, p. 2130].

That is to say, persons interacting with one another do create roles for themselves in response to what they take to be the role expectations which others have of them.

The physicians in The Netherlands, for example, were able to see themselves from the perspective of the helpless relatives of a comatose patient. They were able to take the role of the relatives, make an assessment of their own ability as seen from the relatives' perspective, and say to themselves that they had the authority to bring an end to the "senseless 
prolongation' of the patient's life if they wanted to. They could then modify their own role of humanitarian-medical-expert so as to enlarge the humanitarian part of it. Instead of role enlargement we might even see this as a case of a role overlap in which the role of humanitarian predominates over the roles of the medical expert and law-abiding citizen, all of which roles are occupied by the physician continually. The role of humanitarian might be adopted as predominant over the other roles in justifying the practice of an illegal form of euthanasia (see Nelson and Hiller for a detailed discussion of role overlap)

${ }^{14}$ Before the heroin addict (of endnote 2) has ever tried heroin, other things being equal, his behaviour may be placed near the A-end of the continuum; but after he becomes "hooked" his behaviour may be placed near the Z-end. Now habituated in a particular way of life predictions about his behaviour are much more likely to be true than otherwise would be the case. This has importance not only for individuals but for society as a whole and bears significantly upon the question of the strength which $M C S A$ possess.

${ }^{15}$ I saw the article in The Medicine Hat News, Dec. 13, 1986. The word "stability" is qualified because in most instances the traits are not so stable that it is impossible for the owner of them, either by inner resolve or outer circumstances, or both, to destabilize them. However after they seem to become stable through long habituation, their influence will exert upon the individual a definite propensity or push in a particular direction which critics of MCSA musn't overlook. And if many such individuals are similarly inclined by negative traits, then society needs to worry.

${ }^{16}$ While not wanting to argue that people are victims of their traits, nonetheless, I do wish to say that, barring unusual circumstances, the negative behaviour of those who have been habituated thus to behave can be predicted with sufficient confidence that the MCSA which appropriately refer to such behaviour gain a corresponding measure of credibility and strength.

${ }^{17}$ Most people do believe in the integrity of human behaviour, whether or not they precisely know it or talk about it. We don't assume that permission to be cruel to cats and dogs doe not have a spill-over effect upon our treatment of higher animals. And some people are telling us quite forcefully that a steady diet of TV violence will develop attitudes which manifest themselves outside the living room. This raises the question of desensitization which we shall discuss next.

${ }^{18} S D$ actually involves a three-step process: "(1) Building anxiety stimulus hierarchies, (2) Learning deep muscle relaxation, (3) Visualizing scenes from your hierarchy while deeply relaxed". This process and the theory behind it are explained clearly in Self-Directed Systematic Desensitization (Wenrich et al, p.19)

19) After presenting some evidence for the harmful effects of viewing violent erotica, Taylor et al observe that, "even if violent erotica does not directly contribute to violence it might contribute to the desensitization of men to violence against women. It might lead to demeaning or callous attitudes toward women and therefore make violent or coercive sexual behaviour more acceptable...studies have found that repeated exposure over a period of days or weeks to stag films depicting sexual violence against women produce desensitization in terms of reducing perceptions that the material was violent and degrading to women, reducing support for sexual equality, and lessening sympathy for victims of rape (e.g., Linz, Donnerstein, \& Penrod, 1984; Zillmann \& Bryant, 1982; see Malamuth \& Brieve, 1986, for a review)" (pp.462-63)

${ }^{20}$ Similarly, not much can be proven about the destructive effects of pornography by wiring up prisoners' penises, flashing erotic pictures on a screen and then trying to measure subsequent behaviour. Yet many prisoners will affirm that a steady diet of pornography over a long time did have a destructive effect upon their development.

${ }^{21}$ Analogously, we cannot see the sun move across the sky (or the earth move relative to the sun). This is because the rate of the sun's motion is below our threshold for perceiving motion, and not because no motion has occurred. The motion can be indirectly demonstrated by measuring the movement of shadows. Moral slides can also be indirectly demonstrated to have occurred by making properly spaced observations. Showing that they have occurred (or that likely they will occur) is not, of course, to explain why they have occurred. It will have been evident from the outset that it was not my principal aim to tackle the whyquestion.

I am indebted to Bill Baker for the points about the limitation of the scientific approach in the matter of measuring desensitization.

${ }^{22}$ One of the things that frightens us about reading Orwell's 1984 or watching Kubrick's $A$ Clockwork Orange is that we know that the acts of inhumanity which these works portray really could occur.

${ }^{23}$ Reported in The Edmonton Journal, Thursday, June 23, 1994.

${ }^{24}$ Despite the inherent difficulties in measuring public opinion about abortion, data do exist from which one can draw the general conclusion that attitudes toward abortion have become much more favorable over the past two to three decades. [Costa(124), Sachdev (163-67), Hoffmeier, Bernardi, Gardner (anecdotal, 72,73)]. Gionelli's coverage of a recent conference of abortion providers (NAF) is an eye-opener in this regard.

Perhaps more telling of public opinion than even the answers to questionnaires are the available statistics on the number of abortions performed. In the United States, from the early 1970 s to the early 1980 s the number of abortions rose dramatically, from about $.2-.5$ million to about 1.4-1.6 million (depending upon the survey), stabilizing at the last figure (Costa, p.81f.). "In 1992, 100,197 Canadian women had abortions, a 5.7 percent increase from 1991. The national abortion rate almost doubled between 1972 and 1992 , to 25.3 for every 100 live births from 13.1 for every 100 births" (from Statistics Canada, as quoted in The Edmonton Journal, Oct. 6, 1994).

${ }^{25}$ Another analogous feature, shared by the arguments of the early abortion advocates and the current arguments of $V A E$ advocates, was illustrated recently in The Canadian Press. "Arn Schilder of B.C. Persons with AIDS...said botched back-alley suicides and horrible acute care deaths will continue if the status quo is maintained." (Reported in The Edmonton Journal, Thurs., Sept. 29, 1994.)

${ }^{26}$ The same problem, to a lesser degree of seriousness, is manifested in the use of disposable diapers. "They were introduced and first advertised, by the companies that make them, simply as emergency devices, to be used only in a very limited number of situations" (an example given to me by Trudy Govier).

${ }^{27}$ This problem makes the project of grounding moral absolutes, undertaken by thinkers like Kant, seem reasonable. At a societal level we can protect our sensitivities against genocide, for example, by perpetually enforcing an absolute law which condemns it. But this perpetual enforcement itself will succeed only if we continually preserve our conviction that such a law is worthy of being upheld continually. Ultimately a principle promoting the great intrinsic value of human life will have to be both articulated and internalized by each succeeding generation in order for our sensitivities against genocide to be protected in perpetuity.

There are three possibilities with respect to past/present moral principles/rules being held in perpetuity: (1) none of them should be so held; (2) all of them should be so held; (3) some of them should be so held. "(1)" seems implausible because we should always want to prohibit the torturing of children just for fun, to mention only one principle or rule which I assume most people for good reason would not find it difficult to call a moral absolute. "(2)" seems implausible because I assume most people for good reason do not think that we should execute those who commit adultery, to mention only one principle which has been upheld in more than one society in the past. "(3)" seems to be the plausible alternative. As to precisely which principles should be given the quality of absoluteness, and exactly how many there 
are, I cannot say; but I am prepared to say what I think some of the candidates for consideration should be. Moreover, I don't see it as beyond the realm of possibility that a large number of people in a society, possibly most of them, could come to an agreemen about what the main ones should be (I hope that the vast majority of people in our society would agree with the one l've stated above).

The relevant cautionary note is in order here. Even if every nation of the world agreed at time $t$ that principles $a \ldots n$ should be upheld in perpetuity-an unrealistic assumption, admit - we would still have no guarantee that the nations of the world at $t+j$ would honour the list previously agreed upon, instead of, e.g., proposing an abbreviated list $a \ldots k$. This takes us back to the urgent need to be vigilant about perpetually reinforcing the moral sensitivities we wish to preserve.

${ }^{28}$ I am very grateful to Trudy Govier for her constructive criticisms of the first two drafts of this paper; and to Bill Baker and Ralph Johnson for their constructive criticisms of the first and second draft respectively. I also wish to thank Jonathan Strand, Joseph Buijs and Henry Schuurman for helpful discussions on the second draft.

\section{REFERENCES}

Berger, Edward M. and Gert, Bernard M., "Genetic Disorders and the Ethical Status of Germ-Line Gene Therapy", The Journal of Medicine and Philosophy, Vol. 16, 1991, pp. 667-83.

Bernardi, Peter J., "Coming Soon: Your Neighborhood Termination-of-Suffering Clinics", America, Vol. 170, No. 15, April 30, 1994, pp. 6-9.

Black, Max, "Reasoning With Loose Concepts", Dialogue: The Canadian Philosophical Review, Vol. 2, 1963, pp. 1-12.

Burgess, J.A., review of David Lamb's Down the Slippery Slope, Australian Journal of Philosophy, Vol. 69, No. 1, 1991, pp. 113-14.

Campbell, J.B., "Cognitive Dissonance", Encyclopedia of Psychology, Vol. 1, editor, Raymond J. Corsini, (New York, NY: John Wiley \& Sons, 1994), pp. 249-50.

Cargile, James, "The Sorites Paradox", The British Journal for the Philosophy of Science, Vol. 20, 1969, pp. 193-202.

Costa, Marie, Abortion: A Reference Handbook, in the Contemporary World Issues series, (Denver, CO: ABC-CLIO, 1991).

Dworkin, Gerald, "Dangerous Ground?", review of David Lamb's Down the Slippery Slope, Hastings Center Report, Vol. 20, No. 3, May/June 1990, pp. 42-43.

Fenigsen, Richard, "The Report of the Dutch Governmental Committee on Euthanasia", Issues in Law and Medicine Vol. 7, No. 3, Winter 1991, pp. 339-44.

Freeman, James B., Thinking Logically, (Englewood Cliffs, NJ: Prentice Hall, 1988), pp. 91-94.

Gardner, R.F.R., Abortion: The Personal Dilemma, (Grand Rapids, MI: William B. Eerdmans, 1972).

Gionelli, Diane M., American Medical News, published by the American Medical Association, July 12, 1993.

Govier, Trudy, A Practical Study of Argument, 2nd. ed., (Belmont, CA: Wadsworth Publishing Company, 1988), pp. 304, 305.

"What's Wrong With Slippery Slope Arguments?", Canadian Journal of Philosophy, Vol. 12, No. 2, June 1982, pp. 303-16.
Graham, A.C., "History of Logic" [Megarians], The Encyclopedia of Philosophy, Editor in Chief, Paul Edwards (New York, NY: Macmillan Publishing Company, 1967), Vol. 4, p. 518 .

Hare, R.M., "Abortion and the Golden Rule", Philosophy and Public Affairs, Vol. 4, No. 3, 1975, pp. 201-22.

Hergenhahn, B.R., An Introduction to Theories of Personality, 3rd. ed., (Englewood Cliffs, NJ: Prentice-Hall, 1990).

Hoffmeier, James K., editor, Abortion: A Christian Understanding and Response, (Grand Rapids, MI: Baker Book House, 1987).

Huffman, K., Vernoy, M., Williams, B., \& Vernoy, J., Psychology in Action, 2nd. ed., (New York, NY: Wiley, 1991).

Hurley, Patrick J., A Concise Introduction to Logic, 3rd ed., (Belmont, CA: Wadsworth Publishing Company, 1988), pp. 159, 160.

Jacquette, Dale, "The Hidden Logic of Slippery Slope Arguments", Philosophy and Rhetoric, Vol. 22, No. 1, 1989, pp. 59-70.

"Epistemic Blood from Logical Turnips", [response to Sorensen], Philosophy and Rhetoric, Vol. 22, No. 3, 1989, pp. 203-11.

Johnson, R.H., and Blair, J.A., Logical Self-Defense, 2nd ed., (Toronto, Ont.: McGrawHill Ryerson Ltd., 1983), pp. 160-66.

Kneale, William and Martha, The Development of Logic, [Eubilides], (London: Oxford University Press, 1962), pp. 16, 113, 114.

Lamb, David, Down the Slippery Slope: Arguing in Applied Ethics (London: Croom Helm Ltd., 1988).

Levett, Bruce, The Canadian Press, "[Killer cons] PM into a visit", Medicine Hat News, December 13, 1986

Marquis, Don, "Why Abortion Is Immoral", The Journal of Philosophy, Vol. 86, No. 4, 1989.

Nelson, John J. \& Hiller, Harry H., "Norms of Verbalization and the Decision Making Process in Religious Organizations", Journal for the Scientific Study of Religion, Vol. 20, No. 2, 1981, 173-80.

Rachaels, James, "Euthanasia", Matters of Life and Death, 2nd. ed., editor Tom Regan (New York, NY: Random House, 1986).

Rudinow, Joel, "On 'The Slippery Slope'”, Analysis, Vol. 34, 1974, pp. 173-76.

Sachdev, Paul, editor, Perspectives on Abortion, (London: The Scarecrow Press, Inc., 1985).

Sneiderman, Barney, "Euthanasia in The Netherlands: A Model for Canada?", Humane Medicine, Vol. 8, No. 2, April 1992, pp. 104-15.

Sorensen, Roy A., "Slipping off the Slippery Slope: A Reply to Professor Jacquette", Philosophy and Rhetoric, Vol. 22, No. 3, 1989, pp. 195-202.

Stryker, Sheldon, "Symbolic Interaction Theory", Encyclopedia of Sociology, Vol. 4, editors Edgar F. Borgatta \& Marie L. Borgatta, (New York, NY: Macmillan Publishing Company, 1992), pp. 2127-34.

Swazey, Judith P., Anderson, Melissa S. \& Lewis, Karen S., "Ethical Problems in Academic Research", American Scientist, Vol. 81, November-December, 1993, pp. 542-53. 
Taylor, S.E., Peplau, L.A., \& Sears, D.O., Social Psychology, 8th ed., (Englewood Cliffs, NJ: Prentice Hall, 1994).

ten Have, Henk A.M.J. \& Welie, Jos V.M. "Euthanasia: Normal Medical Practice?", Hastings Center Report, Vol. 22, No. 2, March-April 1992, p. 36.

Trianosky, Gregory W., "Rule-Utilitarianism and the Slippery Slope", The Journal of Philosophy, Vol. 75, No. 8, August 1978, pp. 414-24.

van der Maas, Paul J. \& van Delden, Johannes J.M. \& Pijnenborg, Loes \& Looman, Caspar W.N., "Euthanasia and other medical decisions concerning the end of life", The Lancet, Vol. 338, No. 8768, September 14, 1991, pp. 669-74.

Walton, Douglas, "Splitting the Difference", Dialogue, Vol. 20, No. 1, 1981. . Slippery Slope Arguments, (Oxford: Clarendon Press, 1992).

Wenrich, W.W., Dawley, H.H., \& General, D.A., Self-Directed Systematic Desensitization: a guide for the student, client and therapist, (Ann Arbor, MI: Edwards Brothers, 1976).

Weiss, Stephen E., "The Sorites Fallacy: What Difference Does a Peanut Make?", Synthese, Vol. 33, 1976, pp. 253-72.

Zimbardo, Philip G., Psychology and Life, 12th ed., (USA: Harper Collins Publishers, 1988).

GARY COLWELL DEPARTMENT OF PHILOSOPHY CONCORDIA UNIVERSITY COLLEGE OF ALBERTA 7128 ADA BOULEVARD. EDMONTON, ALBERTA T5B $4 E 4$ 